\title{
The American addiction food
}

\section{Opinion}

Everyone knows we have to eat to survive. But it is what we eat that determines our Health \& Wellness. Many of us are familiar with alcoholics, drug abusers and other unhealthy addictive behaviors. How many recognize that unhealthy foods can be just as, and often more addictive than drugs?

We live in an addictive society. Kids are addicted to their smart phones, not to books. Adults are addicted to many other, often selfdestructive behaviors. Most people recognize the more benign addictions, like work, smart phones, social media and other addictive behaviors and accept them as the new normal.

Food addictions are almost never seen as such. Most Americans are actually addicted to three things: sugar, fats and salt, but fail to recognize it. Fast foods and common processed foods are chock Full of salt, sugar and fat. They taste so good that you just want more and more. Many folks can't go without their soda drinks as the sugar gives a boost of energy, but like any other addictive drug, you will crash when the blood sugar spike is over; so you drink another soda.

Fast Food burgers, fries and soda for breakfast, lunch or dinner is just as addictive. White breads are like raw sugar to your system. The meat, cheese, eggs are full of fat, often heavily salted and contain no fiber. The big-gulp sodas are Full of sugar. It's actually feeding your addiction and because the sugar high only lasts a short time, you crave more and more. The meat, cheese, eggs contain NO fiber so you get all the calories and fat, cholesterol but never fill up. So you eat more and more and still are hungry a short time later.

This is the additive behavior that is making Americans Fat, Sick and Nearly DEAD. The more you crave, the more you eat. The more you eat the more pounds you put on. You might be able to work a lot of the calories off at the gym but your internal organs and arteries are clogging up. This is a fast track to Death or Disability.

\section{Twelve steps programs}

Many folks are familiar with the various addiction treatment programs. Alcoholics Anonymous pioneered a 12-Step program that has been helping people for decades. The Serenity Prayer begins with "God grant me the serenity to accept the things I cannot change; Courage to change the things I can; And wisdom to know the difference."

We cannot change the need to consume food but we can change what we eat. It is the understanding and wisdom to recognize which foods will sustain us and which ones will hurt us; eventually leading to premature death and/or disability.

The AA program has a mantra for those first trying to get sober, quite drinking and change the addictive behavior that is often destroying their lives. It is simply this: "90 meetings in 90days" which means you must dedicate yourself to Change. Since change is never easy, you must focus and commit time and effort to change direction, eliminate bad habits and create new healthier ones. It all comes with education and dedication to improve your health and wellbeing for YOU first before you can elicit/encourage change in others (family \& friends).
Volume 6 Issue I - 2017

\author{
Skip Stein \\ Plant Based Lifestyle Consultant, Whole Foods 4 Healthy Living, \\ USA
}

Correspondence: Skip Stein, Plant Based Lifestyle Consultant, Chief Operating Officer, Whole Foods 4 Healthy Living, Orlando, USA, Tel 4076836816, Email SkipStein@newtimers.org

Received: January 10, 2017| Published: January 27, 2017

\section{Lifestyle change}

The Foundation of this lifestyle change is a Whole Foods Plant Based diet. A foundation in healthy Whole Foods and the elimination of all meat, fish, dairy and eggs and derivative products is essential. If you aren't currently suffering from a lifestyle disease you might gradually migrate to this healthier dietary lifestyle; but if you are suffering from cancer, heart disease, diabetes two or other ailment, a more aggressive approach may be best.

The beauty of Lifestyle Change that starts with diet and what you eat, is that you don't have to go it alone. Food addictions tend to be social and impact the family unit and community. It only takes one to initiate change and to be a model for others. Encouraging others to join you in a path to health $\&$ wellness is best done by example.

If you get push-back from family and friends sometimes you just have to go it alone or maybe find some new friends; at least for a time. When you begin to exhibit more energy, your appearance improves, you might lose some weight and just feel happier; others will notice. The most important thing is that You will notice the improvement quickly.

While an initial commitment to at least 90days is optimal, most individuals will experience dramatic results in weeks. Often diabetes 2 can be fully reversed in just 16 to 30 days. Clearing clogged arteries and weight loss is more gradual and takes longer. I can almost guarantee that in 90days you will see dramatic improvement in all aspects of your life. You will see it in black \& white when you get updated blood analysis with your doctor!

\section{Lifestyle - not just diet}

To optimize your lifestyle change you need to consider more than just the food you consume. We are talking Lifestyle, not just a dietary change! Your first 90days is just the beginning of the Rest of Your Life; and you can expect a long and healthy one.

Exercise, just getting up and moving is critical to so many things. You don't need a gym membership, just a safe place to walk. Just MOVE, even if it's getting up from your desk and walking to the furthest water fountain once an hour. MOVE. Get out at lunchtime and take a stroll; a quick pace is better! 
Many people may consider more formal exercise programs. Yoga is great as is Tai Chi, Chi Gong and other low impact routines. As you explore these alternatives, an introduction to meditation and relaxation routines will also help reduce stress and improve your overall outlook of Life!

It all works together to improve your health, wellness and longevity. I can guarantee you will have more energy and these augmentations to your lifestyle will come naturally. You will really want to MOVE.

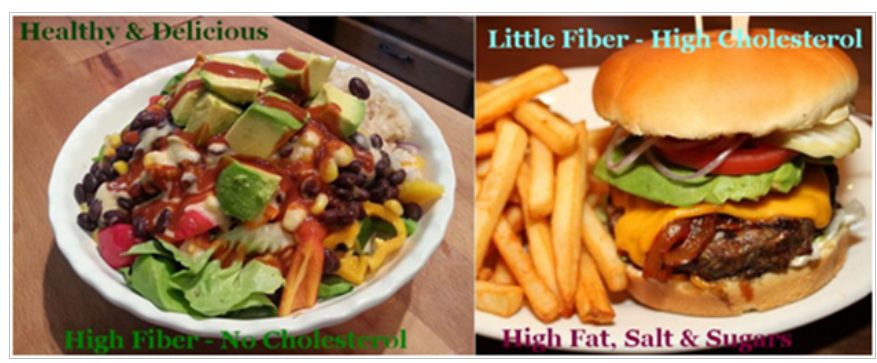

Figure I American food.

\section{If you need help - just ask}

Sometimes you need help getting started and maintaining your focus. Encouragement and Coaching can be helpful to support this change in Lifestyle. Just like any other program, a Lifestyle Coach may prove beneficial. Sometimes just talking about it and seeing how others accomplished Change can be encouraging.

You may need help selecting a healthier food, training on how to prepare delicious meals at home. How to order healthier fare from almost any restaurant menu and more. We are here to help, guide you and provide lots of information.

We have done what we encourage you to do. Provide an example to your family and friends because as you get healthier, more energetic and happier, others will want to do as you have done. Help others and Pay It Forward!

\section{Acknowledgements}

None.

\section{Conflict of interest}

Author declares that there is no conflict of interest. 